\title{
The safety of pharmaceutical excipients
}

\author{
Giorgio Pifferi $^{\mathrm{a}, *}$, Patrizia Restani ${ }^{\mathrm{b}}$ \\ a Institute of Pharmaceutical and Toxicological Chemistry, V.le Abruzzi 42, Milan, Italy \\ ${ }^{\mathrm{b}}$ Department of Pharmacological Sciences, Via Balzaretti 9, Milan, Italy
}

Received 30 June 2002; accepted 30 September 2002

\begin{abstract}
The most important part of a medicine as far as its weight is concerned, is constituted by its excipients, which have the important functions of guaranteeing the dosage, stability and bioavailability of the active principle. The components employed as excipients must present the characteristics required by their technological function but, as with any substance administered to man, they must also correspond to suitable safety requirements. In fact, in the past the importance of evaluating the possible adverse effects of excipients was underestimated, because their inertia and innocuity were taken for granted. The safety profile of these substances is more deeply researched as regards the toxicological aspect only if they are also employed in the food industry (anti-oxidants, sweeteners, colouring agents, etc.). Indeed, in this case, the International Toxicological Committees (among which the Joint Expert Committee on Food Additives, a mixed committee of the WHO/FAO) demand thorough studies in laboratory animals, with the intent of protecting the consumer's safety. Tackling the question of the toxicity of excipients thoroughly is not a simple matter for several reasons: the large number of substances on the market and the diversity of their chemical profiles, their sources, their technological functions, and the presence of secondary products and/or contaminants that may be the true causes of adverse effects. In this article we shall review the principal classes of excipients and their respective side effects. Then we shall proceed to their toxicological evaluation, giving examples of: (a) intrinsic toxicity, or adverse effects that may be encountered in the whole population; and (b) specific toxicity, which manifests only in people who are carriers of a transmissible disease or who are genetically predisposed, such as people with allergies and intolerances.
\end{abstract}

(C) 2003 Éditions scientifiques et médicales Elsevier SAS. All rights reserved.

Keywords: Safety; Pharmaceutical excipients; Toxicity

\section{Definition of excipient}

The term comes from the Latin word excipiens, present participle of the verb excipere which means to receive, to gather, to take out. This refers to one of the properties of an excipient, which is to ensure that a medicinal product has the weight, consistency and volume necessary for the correct administration of the active principle to the patient. In 1957, excipients were defined as 'the substance used as a medium for giving a medicament', that is to say with simply the functions of an inert support of the active principle or principles [1]. Again, in 1974 they are described as 'any more or less inert substance added to a prescription in order to

\footnotetext{
* Corresponding author.

E-mail address: pifferi@mailserver.unimi.it (G. Pifferi).
}

confer a suitable consistency or form to the drug: a vehicle' [2].

This historically somewhat limiting definition referred to those substances employed in the preparation of pills, a now obsolete pharmaceutical dosage form later replaced by tablets and capsules. Natural products, such as molasses and honey, were long employed in the preparation of pills up to 1940 and USP 10 also mentioned lactose, glucose, lycopodium, glycerin and gelatin [3].

To the function of simple vehicle, galenic science then added that of adjuvant in the carrying and release of the active principle of the formulation. Looking at the matter from this angle, the United States' National Formulary of 1994 states that an excipient is any component other than the active principle added intentionally to the medicinal formulation, or 'everything in the formulation except the active drug' [4]. The 
interpretation of the adverb 'intentionally' brings to mind the multiple rôles that an excipient must play today in a modern pharmaceutical dosage form, suitable to be administered enterally, parenterally and topically. Among these rôles are to be remembered those of guaranteeing the stability, precision and accuracy of the dose, improving the organoleptic characteristics and the patient's compliance. Modern pharmaceutical technology also requires verification of the physical state of the excipient, which is so important both in the manufacturing phase and to control the release of the active principle, with the object of improving the bioavailability and consequently the efficacy and tolerability of the medicinal drug [5].

\section{Origins and sources of excipients}

Generally speaking, excipients account for most of the weight or volume of a medicinal product. In a world pharmaceutical market valued at about $£ 215$ billion, that of the excipients amounts to about $£ 1.5$ billion, $42 \%$ of which in North America, 33\% in Europe and 25\% in the rest of the world [6]. In 1999, all this corresponded to 600 thousand tons of materials most of which for the food, cosmetic and chemical industries and only a small part for the pharmaceutical industry. Excipients are of various origin: animal (e.g. lactose, gelatin, stearic acid), plant (e.g. starches, sugars, cellulose, arginates), mineral (e.g. calcium phosphate, silica) and synthesis (e.g. PEGs, polysorbates, povidone, etc.) and they often lack a trade name. Their origin and use do not often guarantee the quality required by the pharmaceutical industry, which must therefore submit them to more thorough-going analytical controls. In order to carry out the numerous functions required, new classes of excipients have now become available, derived from old and new materials, alone or in combination, adapted to the manufacture of high-performance pharmaceutical dosage forms. Looking at the matter from this angle, excipients can no longer be considered mere inert supports for the active principles, but essential functional components of a modern pharmaceutical formulation. It is also to be borne in mind that the ratio of their weight to that of the active principles is usually very high in a formulation, and such as to cause possible action due to their mass. Like pharmaceutical drugs, they too have their own thermo-dynamic activity which, though generally low, can contribute to reactions leading to degradation or to interactions between the drug and the excipient [7]. In Table 1 the excipients are set out according to their class and the chemical function that can contribute to their reactivity.

Today it is reckoned that over one thousand different materials are used in the pharmaceutical industry to fulfil its various requirements such as diluents, bulking
Table 1

Chemical classification and roles of pharmaceutical excipients

\begin{tabular}{|c|c|}
\hline Chemical classification & Roles to enhance \\
\hline water, alcohols & compliance \\
\hline esters, ethers, carboxylic acids & $\begin{array}{l}\text { dose precision and accu- } \\
\text { racy }\end{array}$ \\
\hline glycerides and waxes & stability \\
\hline $\begin{array}{l}\text { carbohydrates (mono-, di- and polysac- } \\
\text { charides) }\end{array}$ & manufacturability \\
\hline hydrocarbons and halogen derivatives & tolerability \\
\hline polymers (natural and synthetic) & desaggregation \\
\hline minerals & dissolution \\
\hline protein & controlled release \\
\hline $\begin{array}{l}\text { various: preservatives, dyes, sweeteners, } \\
\text { surfactants,... }\end{array}$ & absorption \\
\hline
\end{tabular}

agents, disintegrants, lubricants, colouring agents, sweeteners, etc. They are chemically heterogeneous compounds that go from simple molecules (water) to complex mixtures of natural, semisynthetic or synthetic substances which, from the regulatory point of view, may be subdivided into three categories [8]. In the first category (approved excipients) we find the compounds originating from the food industry (generally recognised as safe: GRAS) or that have been present in pharmaceutical products for a very long time. The intermediate category (essentially new excipients) covers compounds obtained by means of the structural modification of the excipients already approved or those already used in the food or cosmetic industries. The third category covers new compounds, never previously used in the pharmaceutical field and it is growing rapidly due to the present interest in modified-release formulations and the requirements of the modern high-productivity compressing/tabletting machines.

\section{Principal requirements of excipients}

Historically, the importance of excipients in pharmaceutical formulations has generally been underestimated, as they were cheap ingredients viewed solely as inert supports for medicaments. Today, this view is outdated and, on the basis of what we have said above, we may say that excipients are rather more than the sugar in the pill [9].

At this point we may well ask ourselves what the basic requirements of a modern pharmaceutical excipient are. In Fig. 1 the three essential requirements of active principles are compared with those of excipients. Fundamental for both are quality and safety. The requirement of therapeutic efficacy for drugs is replaced by that of functionality for excipients, defined as 'the physical, physicochemical and biopharmaceutical properties' of the same. The concepts of quality and functionality were reviewed by one of the Authors in a 


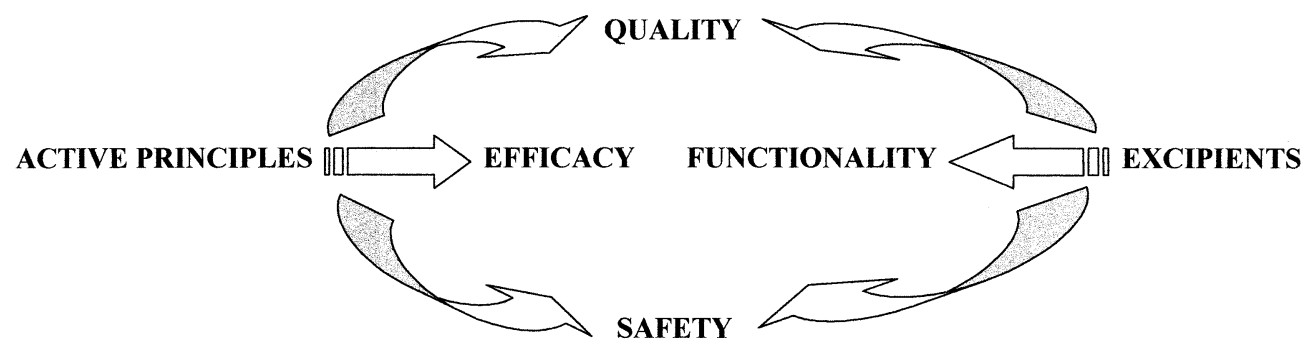

Fig. 1. Main requirements for pharmaceutical excipients.

recent review in this magazine, and those who wish to go more deeply into these aspects are invited to refer to it [10].

Safety has always been the most important requirement and the most studied when dealing with pharmaceutical drugs. Less attention has been devoted to the safety of excipients, because their inertia and innocuity were taken for granted. The considerations made in the preceding paragraphs and the continual evolution of pharmaceutical technology, with the growing use of new 'tailor-made' materials, suggests that a new look at the so-called pharmacological and toxicological inactivity of these components of pharmaceuticals $[11,12]$ is in order. To this end, we shall examine three issues that may compromise the safety of pharmaceuticals: (a) production, distribution and use; (b) pharmaceutical-excipient interactions; and (c) toxicity, which may be the cause of frequent and sometimes notable 'adverse effects'.

\section{Production, distribution and use of excipients}

Side effects imputable to excipients were already noted in the 1930s, as in the case of an elixir of sulfanilamide [13]. A number of deaths occurred in Nigeria and India (1990), in Bangladesh (1992) and in Haiti (1996) because of contaminated solvents, e.g. glycerin containing ethylene glycol [14].

Most excipients are produced in bulk in manufacturing plants that are not devoted to their manufacture. These plants operate with continuous production cycles, and this complicates the traceability of the material, whose quality is often not at pharmaceutical level. Others are isolated from plants or mineral raw materials as opposed to being produced by synthesis [15]. In both cases it is necessary to verify compliance with approved manufacturing guidelines [16,17] and ISO 9002 standards for quality management systems.

Particular attention should be paid to the verification of impurities so as to keep them at an acceptable minimum level [18]. Less worrying is their presence when they are functionally necessary and in any case not toxic, such as hemicellulose in micro-crystalline cellulose. The definition, classification, sources and verification of tolerated levels of impurities are the subject of a recent publication [19] which gives, among other things, the admissible levels of residual solvents in view of their dangerousness.

The distribution phase of materials and finished products, if not controlled, can also be a source of the poor quality, not to say downright toxicity of excipients. Mention has already been made of contaminated glycerin, which caused the death of eighty children due to acute anuric renal failure. From the manufacturer to the distributor and finally to the patient, this substance travels a long way, during which the characteristics of the excipient can be compromised because of unsuitable warehousing and transport conditions, cross contaminations, errors in labelling and in the traceability of lots [20].

Finally, some problems arise from improper use, such as parenteral instead of oral administration of a pharmaceutical containing egg albumin. When a generic pharmaceutical is re-formulated, the properties of the new excipients should be carefully evaluated, especially in the case of modified-release formulations. Furthermore, recourse to the use of 'cocktails' of injectables should be allowed only after careful verification of the chemical and physical compatibility of the active principles and their respective solutions [21].

\section{Pharmaceutical-excipient interactions}

Excipients constitute the mass or greater volume in the usual enteral or parenteral formulations and, as may be deduced from Table 1, they often contain reactive functional groups that may give rise to chemical and physical transformations. Interactions occur more frequently between excipient and active principle than between excipient and excipient and these interactions can be of two types. The physical type of interaction can modify, for example, the speed of dissolution or the uniformity of the dosage of a solid formulation. Indeed, some materials can adsorb drugs to their surfaces, thus increasing the active surface and consequently the wettability and speed of dissolution. The contrary effect may be encountered when the forces of attraction are strong, in which case the drug is released with difficulty and assimilation is compromised. One example is that of 
lipophilic lubricants (e.g. magnesium stearate) which, when finely dispersed on the particles of the active principle, can slow down dissolution and therefore bioavailability.

The chemical type of interaction, on the other hand, can lead to the degradation of the drug and/or the formation of the so-called degradation impurities [1,7]. The most frequently encountered reaction is hydrolisis, because water is the preferred and prevalent solvent in liquid formulations. In solid forms which contain hygroscopic components, the presence of humidity must be controlled and reduced. Even the presence of oxygen, when activated by traces of catalysts (heavy metal ions, light, heat...), may give rise to oxidereduction and the formation of free radicals (e.g. lipidic peroxidation). Other, less frequent, reactions are photolysis, isomerisation and polymerisation, which are more likely to occur with certain types of excipients, lowering the title of the active principle and generating dangerous impurities. One example is the presence of polymeric forms in beta-lactam drugs, such as ampicillin, which are thought to be responsible for dangerous allergic reactions. Ionisable pharmaceuticals may react with ionised soluble excipients giving rise to the formation of insoluble products due to charge interactions. In this way, sodium alginate and neomycin cation precipitate in an acqueous solution.

Another type of interaction may occur between the carbonilic groups of a widely-used excipient like polyvinylpyrrolidone, and pharmaceuticals containing donor groups of hydrogen, like famotidine [22] and atenolol [23], thus causing problems of incompatibility. Even silicon dioxide $\left(\mathrm{SiO}_{2}\right)$, in anhydrous conditions, behaves like a Lewis acid, giving rise to reactions such as hydrolisis, epimerisation, trans-esterification, etc. One example is the hydrolisis of the imino nitrogen link of nitrazepam with consequent disactivation of the drug [24].

However, when evaluating potential pharmaceuticalexcipient interactions, it must however be considered that the kinetics of chemical reactions involving solutions are very high, whereas in the case of solid formulations they are low, if not negligible.

\section{Toxicity of excipients}

A discussion of the toxicity of the excipients employed in pharmaceutical formulations is certainly a difficult and extremely diversified task. To simplify matters, the subject may be organised as follows:

- toxic effects encountered in the whole population;

- toxic effects encountered only in specific populations.
Into the first category fall all the adverse effects proper to chemical, natural or synthetic substances when a certain dose is exceeded. The second category, however, has to do with phenomena that are often independent of, or only marginally dependent on, the dose. That is to say, they are events linked to specific characteristics of the subjects, such as geneticallytransmitted pathologies (metabolic illnesses, among which phenylketonuria and lactose intolerance) or genetic predisposition (among which diabetes and allergic pathologies).

In principle, excipients ought to be subjected to the same toxicity studies as those requested for active principles, so as to protect the population from undesirable effects $[25,26]$. This is assuredly applicable to many compounds, especially those that are used as food additives. However, other substances, that have been used for decades now, can be considered 'safe', given that no adverse effects have been encountered in man.

The excipients that have been authorised to be used as food additives have been evaluated as regards toxicology by the JECFA (Joint Expert Committee on Food Additives), which handles the evaluation of the risk from consuming additives or contaminants with food [27a-d]. In the case of additives, their use is voluntary and has a technological reason, exactly as in the case of pharmaceutical excipients, whereas contaminants are substances that can be vehicled by the food chain, given the ubiquitousness of the distribution of pollutants in the environment. In this article, our preferred source of toxicological data has been the JECFA's conclusions, which take into particular consideration the results of long-term toxicological studies. The JECFA usually terminates its toxicological evaluations with the publication of an admissible daily intake (ADI), which represents the dose that does not carry risks to the population if taken every day for a life-time. This dose is expressed in $\mathrm{mg}$ (or microg) per $\mathrm{kg}$ of daily weight per day. To establish the total daily dose, we should multiply this number by the bodily weight (usually reckoned as $60 \mathrm{~kg}$ ). The value of the ADI is extrapolated from studies conducted in laboratory animals, dividing the highest dose without toxic effects in the animal by a safety factor (generally 100).

\subsection{Toxic effects encountered in the whole population}

In general, it may be said that any compound, and therefore any excipient, can have adverse effects if taken in a sufficiently high dose. This concept was already well known to Paracelsius in the fifteenth century, when he said 'Omnia venenum sunt, nec sine veneno quicquam existit; dosis sola facit ut venenum non sit.' In practice, every substance is a poison, at the right dose.

Adverse effects due to excipients are, fortunately, infrequent and mild, because excipients are generally 
Table 2

Phenolic excipients

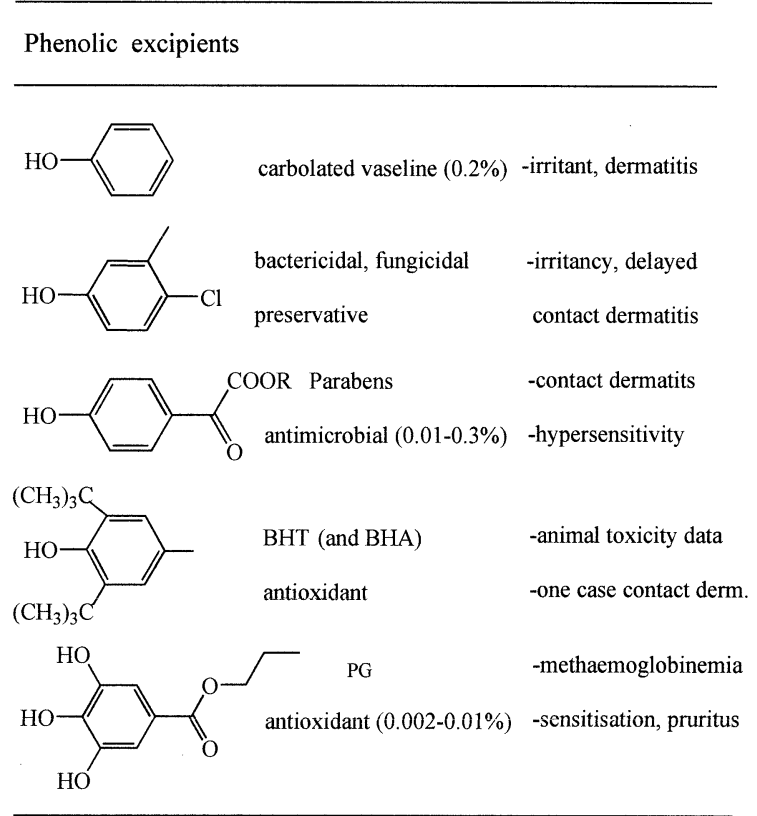

selected because of their low toxicity. Their adverse effects may be imputable to direct toxicity, to immunotoxicity, to allergy or intolerance. As we cannot discuss the toxicity of all the compounds on the market, we shall limit ourselves to giving some examples within the principal chemical classes to which they belong [28]. It is, in fact, possible to think that particular structures and/or substituents characterise both the chemical and physical properties, such as the dissociation constant and the distribution coefficient, and the reactivity of an excipient (e.g. oxide-reduction potential).

A first group of excipients with at least one phenolic function is shown in Table 2 where, besides the structural formulæ, some of the most frequent side effects are listed. These excipients are added to formulations in very low concentrations $(0.01-0.3 \%)$ as antiseptics and for their antioxidant and anti-free radicals activities. Given their antioxidant activity, this category always includes molecules with strong biological activity. The results of experimental studies conducted on laboratory animals with some of these has given rise to some perplexity, their wide use in foodstuffs notwithstanding.

The perplexities surrounding BHA (butyl hydroxyanisol) originated due to the appearance of hyperplasia and carcinoma of the prestomach in rats that underwent chronic treatment with BHA at the dose of $20 \mathrm{~g} / \mathrm{kg}$ diet/ die. Studies conducted in other animal species like man who has no prestomach, such as the pig, the dog and the monkey, however, excluded the possibility of developing hyperplasia of the stomach following chronic administrations of BHA, unless the doses were very high. In any case, deeming that the cancerogenous effect in the rat must not be ignored, the JECFA established an ADI (admissible daily intake) of $0-0.5 \mathrm{mg} / \mathrm{kg}$ body weight/ die, which means about $30 \mathrm{mg} / \mathrm{die} 27 \mathrm{~b}$. A recent evaluation [27d] indicates that the intake of BHA in the average diet can get close to the admissible daily intake. This means that the additional intake of BHA due to pharmaceutical formulations could in some cases be a determining factor in exceeding the levels recommended by the toxicological committees. Particular attention ought therefore to be given to the use of this antioxidant, at least as regards medicines for oral use.

In the case of BHT (butyl hydroxytoluene), the toxic effects most commonly encountered in laboratory animals after chronic administration are lesions to the hepatic cells, which are probably attributable to its inductive action on the hepatic enzymes. On the basis of the various studies taken into consideration, the JECFA defined an ADI of $0-0.3 \mathrm{mg} / \mathrm{kg}$ body weight/day, which means $18 \mathrm{mg} /$ die [27c]. What was said about BHA also applies to BHT, namely that it is necessary to verify whether the use of BHT in pharmaceutical formulations can contribute to exceeding the ADI.

A particular group of antioxidants is composed of sulfites: sodium and potassium bisulfite, sodium and potassium metabisulfite, sodium sulfite and sulphurous anhydride. Sulfites are widely used as antioxidants in both the pharmaceutical and the food industries. For this group of substances, the JECFA has established an ADI value of $0-0.7 \mathrm{mg} / \mathrm{kg}$ body weight/die or $42 \mathrm{mg} / \mathrm{die}$ [27d]. As in the case of BHA and BHT, evaluations have been conducted on the average intake of this group of substances with food. Once again, based on the most conservative reckoning, we find dietary intake values very close to the ADI; therefore in this case, too, the quantity added by pharmaceutical products should be evaluated with the aim of estimating the total intake more closely.

In the case of sulfites, it must be borne in mind that there is an aspect of hypersensitivity concerning the populations at risk (see below). Hypersensitive reactions are characterised by broncoconstriction, pruritis, urticaria, chest pain, angioedema, and hypotension leading sometimes to loss of consciousness. Normally, these reactions concern patients who have already suffered attacks of asthma and usually appear when they eat food containing sulfites. Much less frequent are adverse phenomena associated with the use of sulfites in pharmaceutical preparations [28], often due to 'paradoxical broncospasm' [29].

Numerous compounds with alcoholic function are included among pharmaceutical excipients as solvents and preservatives. Table 3 lists four with their better- 
Table 3

Excipients with alcoholic functions

\begin{tabular}{|c|c|}
\hline $\begin{array}{l}\mathrm{C}_{2} \mathrm{H}_{5} \mathrm{OH} \\
\text { included in hundreds of liquid } \\
\text { pharmaceutical preparations }\end{array}$ & $\begin{array}{l}\text { - drug interactions } \\
\text { - ethanol intoxication (conc. } 25 \mathrm{mg} \text { / } \\
\text { dl) } \\
\text { - cardiac effects by parenteral infu- } \\
\text { sion in patients with heart desease }\end{array}$ \\
\hline $\begin{array}{l}\mathrm{C}_{6} \mathrm{H}_{5}-\mathrm{CH}_{2} \mathrm{OH} \\
\text { at low conc. }(0.9-2 \%) \text { as a } \\
\text { preservative } \\
\text { at high conc. }(\geq 5 \%) \text { as a } \\
\text { solubilizer }\end{array}$ & $\begin{array}{l}\text { - neurological effects } \\
\text { - fatal syndrome in premature } \\
\text { infants at } 99-234 \mathrm{mg} / \mathrm{kg} / \text { day (ben- } \\
\text { zoic acid?) }\end{array}$ \\
\hline $\begin{array}{l}\mathrm{CH}_{3}-\mathrm{CH}(\mathrm{OH})-\mathrm{CH}_{2} \mathrm{OH} \\
\text { as a solvent in i.p., oral, topical } \\
\text { aerosol preparations } \\
\text { as a preservative }\end{array}$ & $\begin{array}{l}\text { - cardiovascular effects by parent- } \\
\text { eral infusion } \\
\text { - neurological effects } \\
\text { - metabolism to pyruvate and lac- } \\
\text { tate } \\
\text { - otologic effects } \\
\text { - thrombophlebitis due to iv diaze- } \\
\text { pam }\end{array}$ \\
\hline
\end{tabular}

$\mathrm{HOCH}_{2}-\left(\mathrm{CH}_{2}-\mathrm{O}-\mathrm{CH}_{2}\right)_{n}-\mathrm{CH}_{2} \mathrm{OH}$

as enhancers for nasal delivery - only mild local toxicity (no oxalic acid)

known relative toxic effects [30]. In this case we shall limit ourselves to giving one example of toxicological evaluation, and shall consider the polyethylenic glycols. Numerous short- and long-term studies have been conducted on these compounds, on several different animal species. It has been observed that toxicity depends in inverse proportion on the molecular weight (the lower the molecular weight, the greater the adverse effects). This phenomenon depends, at least partly, on the lower intestinal absorption of the glycols with higher molecular weight. For this group of compounds, the JECFA has established an ADI of $0-10 \mathrm{mg} / \mathrm{kg}$ body weight/die, or $0.6 \mathrm{~g} / \mathrm{die}$ [27a]. In view of the considerations expressed above, the type and quantity of glycols included in pharmaceutical formulations should be carefully evaluated.

The substances belonging to the group of organomercurial compounds are, by definition, non-inert molecules from the biological point of view, as their principal function is that of inhibiting or arresting the growth of micro-organisms. Many of these have been used for a long time (Table 4) and some are well known to have caused adverse effects in man. Among the most controversial antibacterials, we cannot fail to mention thimerosal, which is often included as an antibacterial in liquids for the preservation and disinfection of contact lenses. Although significant toxic effects on the cornea or epithelial cells have not been encountered, cases of hypersensitivity are frequent among wearers of contact
Table 4

Organic mercurial salts

\begin{tabular}{lll}
\hline Organic mercurial salts & \\
\hline
\end{tabular}

lenses (about $10 \%$ of the population concerned) [31]. Another negative aspect of this compound is the fact that it vehicles mercury, a metal that is well known to be toxic. For example, it has been observed that patients undergoing ophthalmic therapy with products containing thimerosal showed increases in the concentrations of mercury in both blood and tissue [32]. In view of all the negative aspects described above, the use of this antibacterial has been considerably reduced, besides having been banned from numerous pharmaceutical products.

The greater part of halogenated hydrocarbons shown in Table 5 are derived from methane and ethane, which are very stable chemically (apart from their effect on ozone). Freons are volatile lipophilic excipients used as

Table 5

Halogenated hydrocarbons excipients

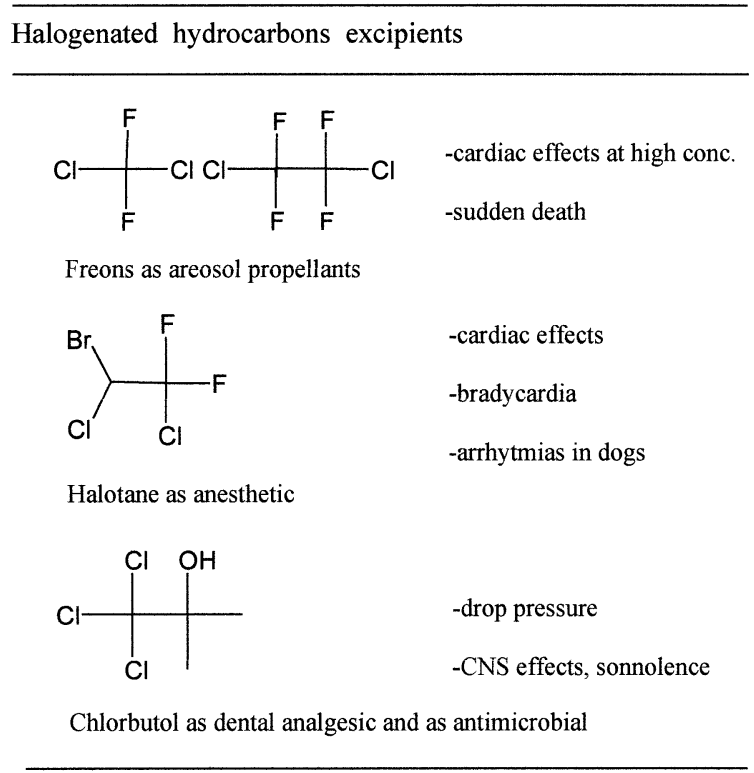


propellants in sprays based on beta-agonists and cortisones. When administered in high concentrations to young patients, they may give rise to rare cases of sudden death [33], which seems due to cardiac effects, particularly arythmias, like those that can be observed with halothane [34]. Chlorbutol is a volatile excipient that has found its use as a bland dental analgesic and as an antimicrobial.

A particular class of excipients is that of the colourants, which are used to improve the aspect of a drug and to avoid confusion during the manufacturing phase or in administration. From the chemical point of view, this class is very heterogeneous for colourants may be of plant, animal or mineral origin, like red and yellow ferrous oxides. Among the synthesised compounds (Table 6) the azoics are included for their excellent colouring properties but they are notoriously well known for causing death among the workers in the manufacturing phase, exposed to contact with intermediates and toxic aromatic ammines. Some colourants were banned in some countries (e.g. Italy) because of their cancerogenous activity encountered in laboratory animals, though not confirmed in man.
In 1971 some cases of intolerance to Premarin ${ }^{\circledR}$ were described: besides oestrogens, this product contained all of 28 excipients. One of these, tartrazine was responsible for the adverse effects [35].

\subsection{Toxic effects encountered only in specific populations}

The case of Premarin and other colourants employed in both the food and the pharmaceutical industries [36] render their inclusion in pharmaceutical products in general inadvisable and more particularly so in antihistaminic preparations, which are aimed mostly at allergic patients. As shown below, these toxic effects concern only some consumers but this does not mean that these effects are less important.

The groups at risk to be considered with attention are people with allergies and intolerances. The former involve the immunitary system, whereas the latter are determined by genetically-transmitted metabolic anomalies (phenylketonuria, galactosemia, etc.) or family predisposition (celiachia, diabetes, etc.).

Contrary to what is generally supposed, the greatest risk from colourants is associated with products of natural origin, because the extraction processes may

Table 6

Dyes and colouring agents

\section{Dyes and colouring agents}

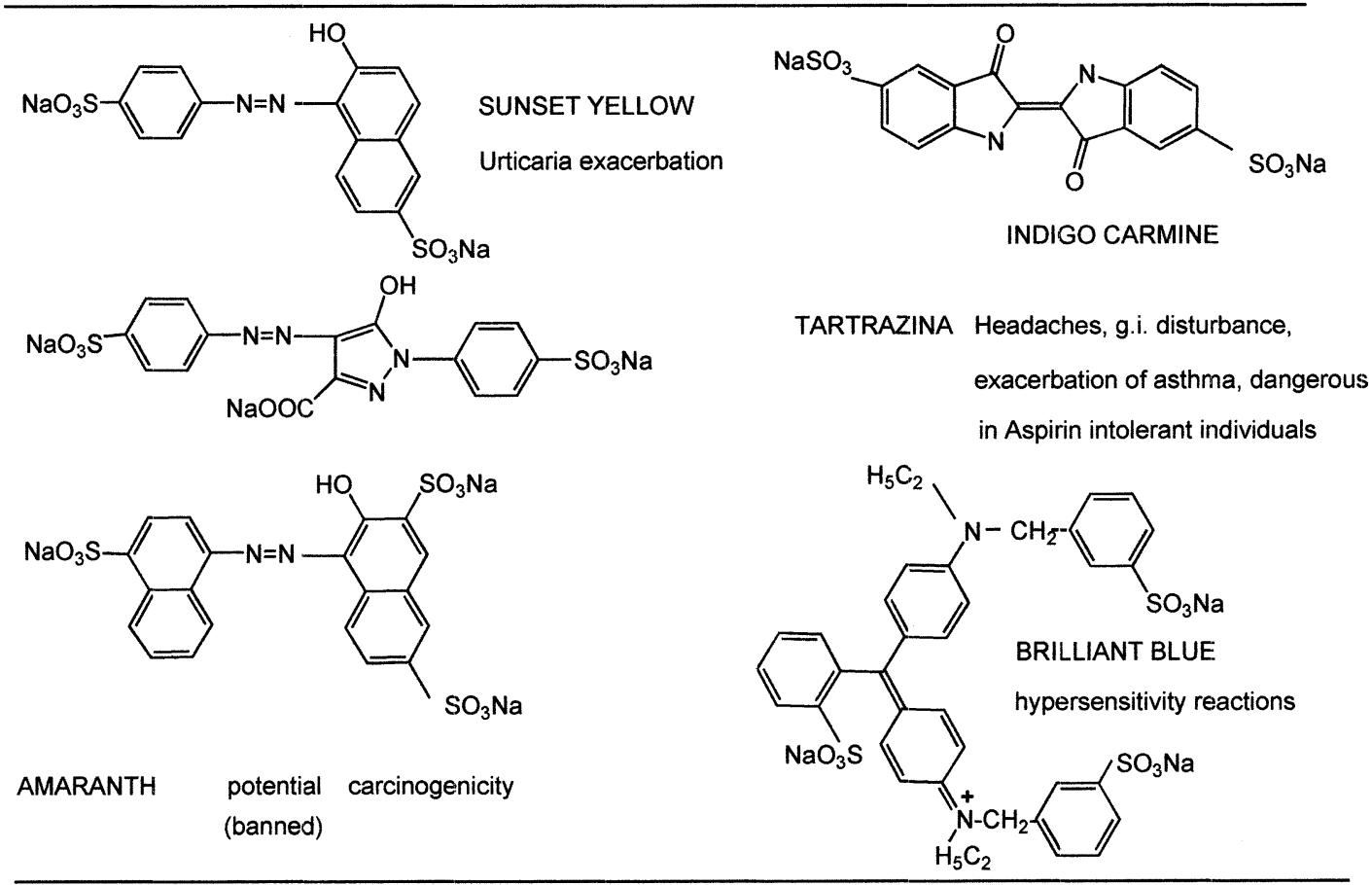


leave traces of proteins, which are mainly responsible for allergic phenomena. In the literature there is the description of the case of an erythromycin syrup which gave some patients bad abdominal pain accompanied by nausea and vomiting, due to the presence of tincture of orange as flavouring [37]. As colouring and flavouring agents do not carry out an important function in a pharmaceutical product, their use should be avoided in products aimed at patients who are already known to suffer from allergic pathologies.

Many of the four thousand or so products used in cosmetics, both natural extracts and those of synthetic origin, are employed as perfumes in formulations for topical use. In this sector, too, adverse effects are known to occur in sensitive populations: the most common clinical symptom is eczematous dermatitis [38]. In order to protect sensitive populations, the perfume should be clearly identifiable from the label but, as said before, the use of perfume should be avoided in any case in antihistaminic products, at least in those that are used to reduce the allergic symptom.

Gluten is a proteic component of wheat to which bearers of celiac illness are sensitive. The classic manifestation of these patients' intolerance is an enteropathology (malabsorption syndrome), but atypical symptoms such as herpetiform dermatitis, iron deficiency anæmia, alopecia and osteoporosis are also encountered. The pathology is linked mainly to gliadine, composed of different proteic fractions, the most toxic of which is the alpha fraction [39]. The therapy for celiac patients consists solely in the elimination of gluten from the patient's diet for the whole of his life. Naturally, abstention from gluten must include abstention from pharmaceutical products that contain gluten among their excipients.

Lactose, a common pharmaceutical excipient, can also induce intolerance due to the physiological diminution of lactase activity in adults. Many patients experience difficulty in tolerating lactose (in Italy, about 70\% of the population), even though symptoms may appear after intake of widely varying amounts [40]. Clinical symptoms: for the more unfortunate even traces of lactose can unleash severe intestinal crises. Consequently, lactose should not be included in antispastic medicaments.

The discovery of BSE (bovine spongiform encephalopathy) and its transmissibility to man have recently brought about restrictive regulations as regards the use not only of lactose but also of bovine gelatin and derivates of tallow [41].

\section{Conclusions}

Medicinal products can be considered a dosed combination of two types of constituents: the active principles and the excipients. The latter are the more important as far as weight is concerned, whether in solid forms, suspensions or solutions. The ideal excipient should be able to fill numerous and important functions, first among which that of guaranteeing the dose, stability and release of the active principle, and the patient's 'compliance'. Furthermore, it should possess particular chemical, physical and mechanical characteristics, so as to optimise the formulation's 'performance' both during the manufacturing phase (manufacturability) and when used by the patient. This multiplicity of roles fits very ill with the traditional galenic view, that saw these 'non-medicinal ingredients' as chemically and pharmaco-toxicologically inert [42].

For a long time now, much attention has been paid to the required quality, efficacy and safety of active principles but only recently has the necessity emerged of examining not only the quality and performance but also the safety of the excipients. The problem is not simple if one considers that in countries like the United States, Japan and Europe there are now in use over a thousand excipients of varying origin, of more or less complex structure and belonging to different chemical classes. About one fifth of them are present in the respective Pharmacopoeiae, which list the pharmaceutical quality requirements but not physical chemistry requirements, much less do they embark on questions of safety. Some information on this aspect may be gleaned from some texts [11,43]. This under-estimation of the safety aspect is also a consequence of the fact that the first excipients were taken from the food industry and therefore considered 'as safe', or else they were already used in pharmaceutical products that had been in therapeutic use for a very long time. Today it is required that any chemically new product whose effects on man are not known must pass all the toxicological tests envisaged for an active principle before it can be accepted as an excipient.

In this paper we have focused our attention on the principal causes that can compromise the safety of excipients [42], first of all the quality of the raw materials on the market, which is often unsuitable for pharmaceutical use. Moreover, these so-called 'inert ingredients' can sometimes interact with the active principles, lowering their titre and generating undesirable impurities, or altering the assimilation processes and the bioavailability of the drug itself. These problems may be overcome by adopting and carefully adhering to good manufacturing practices similar to those for active principles (GMPs).

Very serious risks to the patients can be caused by improper conditions along the distribution chain and the transport of the materials. In this sector, too, some guidelines are being drawn up to guarantee the identity, quality and traceability of lots at any moment, from the manufacturer to the end user. 
It has also been mentioned that the improper use of a medicinal product can be dangerous. In order to avoid this, it is necessary to improve the information about the excipients given on the packaging and the patient's information leaflet, so that doctors, pharmacists and patients know all the ingredients included in a preparation. Furthermore, patients must be instructed to follow prescriptions more closely.

The safety of a medicinal product can also be compromised by the intrinsic toxicity of the excipients themselves. Fortunately, this happens rarely because, by definition, excipients are usually chosen from among the materials noted for being very nearly pharmaco-toxicologically inert. In this article we have elected to subdivide them, where possible, into different classes characterised by a particular chemical function to which their activity can be referred (e.g. halogenic function, phenolic function, etc.). Furthermore, examples of adverse reactions imputable to the intrinsic toxicity of the excipient have been listed as distinct from those due to the specific characteristics of patients. The latter involve cases of genetically-transmitted pathologies of metabolic origin and pathologies due to genetic predisposition, such as rather frequent allergies.

The examples given here point towards the advisability of simplifying formulations as much as possible, so as to reduce the number of excipients to those strictly necessary to fulfil the required functions of the medicinal product. In the same way as for the active principles, the risk/benefit ratio of an excipient should be evaluated on the basis not only of its performance, but also of its safety. It would therefore be useful if the pharmaceutical technologist could avail himself of an inventory of approved excipients, distinguished by a clear international nomenclature (INN system), and listing the relative maximum doses for each administration route.

Another important aspect concerns the regulations and guidelines on excipients already published or in an advanced state of revision, along the lines, duly adapted, of those already available for active principles. The present situation, the advancement of this labour and the forthcoming harmonisation are described in greater detail in numerous reviews, which may be consulted [43-47].

The mass of published papers concerning the safety of excipients is continually on the increase, which goes to show how important and current is this subject that until a few years ago was held to be of scant interest. In this article we have endeavoured to take a new look at some fundamental safety aspects from the pharmaceutical and the toxicological points of view, with the object of contributing to a comprehensive picture of the relative issues.

\section{References}

[1] Morton's, The Nurse Dictionary, 24th ed., Faber \& Faber, London, 1957.

[2] Dorland's Medical Dictionary, 25th ed., W.B. Saunders, Philadelphia, PA, 1974.

[3] C.L. Winek, History of excipient safety and toxicity, Drugs Pharm.Sci. 103 (2000) 59.

[4] L. Blecher, Pharm. Technol. 15 (1991) 54.

[5] G. Pifferi, Eccipienti ieri e oggi, Rapporti GSIRS no. 96-97, Milan, 27 November, 1996.

[6] M.G. Vellvè, The global excipient market: future trends and challenges, Pharmaceutical Techn. Europe, June 2000, pp. 20-24.

[7] P. Crowley, C. Martini, Drug-excipient interactions, Pharmaceutical Techn. Europe, March 2001, pp. 26-34.

[8] P. Baldrick, Pharmaceutical excipient development: the need for clinical guidance, Regul. Toxicol. Pharmacol. 32 (2000) 210.

[9] M.S. Lesney, More than just the sugar in the pill, Today's Chemist at Work, January 2001, pp. 38-43.

[10] G. Pifferi, P. Santoro, M. Pedrani, Quality and functionality of excipients, Farmaco 54 (1999) 1.

[11] M.L. Weiner, L.A. Katkoskie, Excipient toxicity and safety, in: Drugs and Pharmaceutical Sciences, Marcel Dekker, New York, 1999.

[12] G. Pifferi, La sicurezza degli eccipienti, Rapporti GSISR no. 9-10, Milan, 22 May, 2001.

[13] E.M.K. Geiling, P.R. Cannon, J. Am. Med. Assoc. (1938) 916.

[14] Starting Materials for Pharmaceuticals: Control and Safe Trade, WHO PHARM/98.605.

[15] R.C. Moreton, Aspects relating to excipient quality and specifications, Pharmaceutical Techn. Europe, December 1999, pp. 26-31.

[16] Int. Pharm. Excipients Council, Practice Guide for Bulk Pharmaceutical Excipients, 1997.

[17] GMP: Supplementary Guidelines for the Manufacture of Pharmaceutical Excipients, WHO Technical Report Series no. 885

[18] Impurities: Guideline for Residual Solvents, ICH Harmonized Tripartite Guideline, July 1997.

[19] G. Pifferi, A. Mannucci, Drug impurities: problems and regulations, Boll. Chim. Farm. 138 (1999) 500.

[20] Ipec Europe, Good Distribution Practice-A New Challenge to Improve Excipient Safety, Pharmaceutical Techn. Europe, October 2000, pp. 21-24.

[21] G. Pifferi, Compatibilità chimico-fisica tra tiocolchicoside e farmaci antinfiammatori non steroidei, Boll. Chim. Farm. 132 (1993) 203

[22] G. Indrayanto, M. Mugihardjo, R. Handanyi, Drugs Dev. Int. Pharm. 20 (1994) 911.

[23] S. Botha, A. Lotter, Drugs Dev. Int. Pharm. 16 (1990) 1945.

[24] J. Czaja, J.B. Mielck, Pharm. Acta Helv. 57 (1982) 153.

[25] The Safety Committee of the Int. Pharmaceutical Excipients Council, Regul. Toxicol. Pharmacol. 24 (1996) 149.

[26] IPEC-Europe, European Pharmaceutical Review, November 1997, pp. 13-20.

[27] (a) JEFCA, Joint FAO/WHO Expert Committee on Food Additives, 22nd Technical Report Series (1989) 776.;

(b) JEFCA, Joint FAO/WHO Expert Committee on Food Additives, 33rd Technical Report Series, 1995, p. 859.;

(c) JEFCA, Joint FAO/WHO Expert Committee on Food Additives, 51st Technical Report Series, 2000, p. 891.

[28] W.A. Jameson, M.F. Guill, B.B. Wray, Metabisulfite sensitivity: case report and literature review, Annals of Allergy 54 (1985) 115.

[29] American Academy of Pediatrics, 'Inactive' ingredients in pharmaceutical products, Pediatrics 99 (1997) 268

[30] (a) L.K. Golightly, S.S. Smolinske, M.L. Bennett, E.W. Sutherland, III, B.H. Rumack, Pharmaceutical excipients: adverse effects associated with inactive ingredients in drug products, 
Med. Toxicol (Pt. I) 3 (2000) 126;

(b) L.K. Golightly, S.S. Smolinske, M.L. Bennett, E.W. Sutherland, III, B.H. Rumack, Pharmaceutical excipients: adverse effects associated with inactive ingredients in drug products, Med. Toxicol (Pt. II) 3 (1988) 209.

[31] J.R. Miller, Sensitivity to contact lens solutions, West. J. Med. 140 (1984) 791.

[32] D.G. Fagan, J.S. Pritchard, T.W. Clarkson, Organ mercury levels in infants with omphaloceles treated with organic mercurial antiseptic, Arch. Dis. Childhood 52 (1977) 962.

[33] J. Garriot, C.S. Petty, Clin. Toxicol. 16 (1980) 305.

[34] D.M. Aviado, Toxicology 3 (1975) 321.

[35] S.D. Lockey, Am. Allergy 29 (1971) 461.

[36] I. Pollock, E. Young, M. Stoneham, N. Slater, J.D. Wilkinson, J.O. Warner, Survey of colouring and preservatives in drugs, $\mathrm{Br}$. Med. J. 299 (1989) 649.

[37] E. Napke, D.G.H. Stevens, Excipients and additives: hidden hazards in drug products and in product substitution, Can. Med. Assoc. J. 131 (1984) 1449-1451.
[38] W.G. Larsen, Perfum dermatitis, J. Am. Acad. Dermatol. 12 (1985) 1.

[39] S.D. Levenson, et al., Gastroenterology 89 (1985) 1.

[40] S. Ettinger, Krause's Food, Nutrition, and Diet Therapy. Chapter 3, Saunders Company Philadelphia, 2000, p. 37.

[41] European Commission, 97/534/EC, Brussels (1997)

[42] H.J. de Jong, The safety of pharmaceutical excipients, Therapie 54 (1999) 11

[43] A.W. Scott, Non-medicinal ingredients, Drug Saf. 5 (Suppl. 1) (1990) 95

[44] A. Wade, P. Weller, Handbook of Pharmaceutical Excipients, 2nd ed., American Pharmaceutical Association, Washington, DC, 1994.

[45] A. Artiges, Excipients: regulatory aspects, Therapie 54 (1999) 15.

[46] M. Steinberg, J.F. Barzelleca, E.K. Enters, F.K. Kinashita, A. Lopez, D.B. Mitchell, C.B. Tamulinas, M.L. Weiner, A new approach to the safety assessment of pharmaceutical excipients, Regul. Toxicol. Pharmacol. 24 (1996) 149.

[47] J.F. Barzelleca, Development of safety evaluation guidelines, Drugs Pharm. Sci. 103 (2000) 101. 